\title{
CPLP: Presidência rotativa de Timor-Leste e a globalização
}

\section{CPLP: Rotating presidency of East Timor and the globalization}

\section{Agio Pereira ${ }^{1}$}

\author{
${ }^{1}$ Ministro de Estado e da Presidência \\ do Conselho de Ministros do VI \\ Governo Constitucional de Timor-Leste \\ E-mail: agiopereira@gmail.com
}

\begin{abstract}
Resumo
A integração de Timor-Leste na Comunidade dos Países de Língua Portuguesa (CPLP) foi deveras importante tanto para o país quanto para a comunidade. Assumindo a Presidência Rotativa, Timor expandiu os horizontes da CPLP apesar de ser o estado mais novo e de menores dimensões. A par da globalização, floresceu um novo sentido de progresso sem descurar os objetivos anteriormente traçados - concertação político-diplomática, cooperação e reforço da língua portuguesa.
\end{abstract}

Palavras-chave: CPLP; Timor-Leste; Globalização; Organização estratégica.

\begin{abstract}
The integration of East Timor in the Community of Portuguese Language Countries (CPLP) was really important both for the country and for the community. Assuming a Rotating Presidency, Timor expanded the horizons of the CPLP despite of being the youngest and the smallest state. Alongside the globalization, a new sense of progress has flourished without neglecting the objectives that were previously outlined - political-diplomatic consultation, cooperation and reinforcement of the Portuguese language.
\end{abstract}

Keywords: CPLP; East Timor; Globalization; Strategic organization. 


\section{Enquadramento geral}

Se, para nós timorenses, a integração na CPLP foi importante porque nos permitiu, nos últimos 12 anos, ser parte activa da comunidade internacional, com a criação de vínculos mais fortes de fraternidade e sentimentos de pertença a um mundo onde se fala, se sente e se negoceia em português, com casa em África, na América e na Europa, também Timor-Leste oferece um horizonte mais amplo à Comunidade e a cada um dos seus povos membros. ${ }^{1}$

Ao abraçar a Comunidade, logo no momento da sua criação ${ }^{2}$, apesar de apenas se ter formalizado como Estado-membro em 2002, quando foi reconhecido como Nação soberana e independente, Timor-Leste deixou claro, desde sempre, a sua intenção no que respeita a esta organização de países que partilha, na sua génese, e em primeira instância, afinidades linguísticas e culturais. Fazer parte desta Comunidade era um direito tão básico e natural tal como a soberania do País. Contribuir para o seu crescimento era, consequentemente, uma obrigação, também ela básica e natural.

Ao assumir a Presidência Rotativa desta vasta comunidade, apenas doze anos depois de ter finalmente recuperado a sua soberania, Timor-Leste tinha já definido a sua visão para os dois anos de gestão dos caminhos da CPLP. Sem descurar o reforço dos objetivos estabelecidos em 1996, Timor-Leste, o mais novo dos, então, oito Estados-membros, propôs-se oferecer um horizonte mais amplo à Comunidade, "plantando a bandeira da CPLP nos negócios do mundo", como referiu, em 2014, o então Primeiro-Ministro, Xanana Gusmão ${ }^{3}$, poucos dias antes da X Cimeira de Chefes de Estado e de Governo, que decorreu em Díli e que conferiu a Timor-Leste a sua primeira Presidência Rotativa da Comunidade de Países de Língua Portuguesa, sucedendo a Moçambique.

Importa salientar que os nove Estados que compõem, atualmente, a Comunidade (Angola, Brasil, Cabo Verde, Guiné-Bissau, Guiné Equatorial - aceite em 2014, Moçambique, Portugal, São Tomé e Príncipe e Timor-Leste) estão situados em quatro continentes (África, América, Ásia e Europa). Estes nove países - a Comunidade - têm mais de 230 milhões de habitantes. Mas a verdade é que a abrangência da CPLP vai muito para além destas fronteiras, por meio das várias comunidades regionais a que os seus Estados pertencem: em África, Cabo Verde e Guiné-Bissau pertencem à Comunidade Económica dos Estados da África Ocidental CEDEAO, a Guiné Equatorial e São Tomé e Príncipe pertencem à Comunidade Económica dos Estados da África Central - CEEAC, e Angola e Moçambique pertencem à Comunidade para o Desenvolvimento da África Austral (conhecida por SADC, do seu nome em inglês, Southern Africa Development Community); na América, o Brasil está no Mercado Comum do Sul MERCOSUL, na Europa, Portugal pertence à União Europeia - UE, e na Ásia, Timor-Leste está a formalizar a sua entrada na Associação de Nações do Sudeste Asiático, conhecida por ASEAN: Association of Southeast Asian Nations. Por meio destas comunidades regionais, a CPLP chega a 86 países - cerca de 2,2 mil milhões de pessoas, cerca de $31 \%$ da população mundial.

Também em termos económicos, a CPLP tem uma posição relevante. Segundo as contas do 'World Economic Outlook' de outubro de 2016, as nove economias dos países da CPLP valem cerca de três biliões de dólares (2,7 biliões de euros).

\footnotetext{
${ }^{1}$ In: "Política de Timor-Leste na Liderança da CPLP: uma Visão Global para o Futuro" - Discurso de Sua Excelência o Primeiro-Ministro, Kay Rala Xanana Gusmão, por ocasião da Conferência Científica Internacional sob o tema "Investigação, Educação, Cooperação e Desenvolvimento nos Países de Língua Oficial Portuguesa", 16 de julho de 2014, Universidade Nacional Timor Lorosa'e (UNTL), Centro de Convenções de Díli.

2 Estiveram presentes, como observadores, na I Cimeira de Lisboa, o Doutor José Ramos-Horta, o Dr. José Luís Guterres, o Dr. Mari Alkatiri e o Dr. Roque Rodrigues.

3 In: "Política de Timor-Leste na Liderança da CPLP: uma Visão Global para o Futuro" - Discurso de Sua Excelência o Primeiro-Ministro, Kay Rala Xanana Gusmão, por ocasião da Conferência Científica Internacional sob o tema "Investigação, Educação, Cooperação e Desenvolvimento nos Países de Língua Oficial Portuguesa", 16 de julho de 2014, Universidade Nacional Timor Lorosa'e (UNTL), Centro de Convenções de Díli.

E3 - Revista de Economia, Empresas e Empreendedores na CPLP | Volume 3 | Número 1
} 
Foi nesta perspetiva global da Comunidade que Timor-Leste se concentrou, na altura de planear a sua entrada na gestão dos destinos da CPLP. Apesar de ser o Estado mais novo e de menor dimensão dos nove - com pouco mais de um milhão de habitantes, num território terrestre com pouco mais de15 mil Km2, e de se debater, ainda, como uma situação interna de consolidação das instituições -, a sua experiência ao nível da participação ativa em fóruns como a Iniciativa de Shangri-La, em Singapura, e o Diálogo Internacional de Defesa de Jacarta, e em organizações internacionais, como o $\mathrm{g} 7+$, do qual é membro fundador, suscitaram aos líderes nacionais perspetiva e vontade de levar a Comunidade para novos caminhos.

Dias antes de Timor-Leste assumir a Presidência, em 2014, o então Primeiro-Ministro, Xanana Gusmão, refletia sobre o contexto mundial que se vivia (e vive), marcado pela mudança e pelas convulsões, enquadrando-o nas expectativas de Timor-Leste para as responsabilidades que se preparava para assumir. Era claro para Timor-Leste o desafio que enfrentava. É intrínseco a Timor-Leste transformar os desafios em oportunidades.

Desde logo, a nível interno, Timor-Leste não podia ignorar a sua recente independência e as circunstâncias em que foi conseguida. Apesar de pertencer ao passado e apesar da resiliência e capacidade de superação do povo timorense, nas conquistas recente e consecutivamente alcançadas, estas circunstâncias ainda ecoam e, naturalmente, podem condicionar o caminho do progresso que a nação desenhou, expresso no seu Plano Estratégico de Desenvolvimento para 2011-20304.

A pouca experiência ao nível do jogo político internacional da maioria dos novos dirigentes, os constrangimentos orçamentais e, especialmente, a insuficiência de recursos humanos qualificados, constituiu um obstáculo de dimensões consideráveis para a Presidência Timorense. A consolidação das instituições deste que é o mais jovem dos nove Estados que compõem a Comunidade, a reconstrução e desenvolvimento da Nação - fragilizada pela luta da guerrilha, como para grande parte dos nove Estados, apesar de motivos diferentes progrediu a par com a gestão da CPLP e, ainda, de outros compromissos internos, - como o estabelecimento definitivo de fronteiras terrestres, com a Indonésia, e marítimas, com a Indonésia e com a Austrália -, e externos como a participação ativa no g7+ ou o processo de candidatura à ASEAN.

Durante a Presidência de Timor-Leste na CPLP, em fevereiro de 2015, houve uma mudança de Governo que fugiu ao normal calendário eleitoral, sem que esse factor político interno, que decorreu em circunstâncias e de forma extraordinárias, se repercutisse na Presidência da Comunidade. De uma forma bem organizada e consensual, considerando todas as implicações internas e externas, o Primeiro-Ministro, Kay Rala Xanana Gusmão, passou o testemunho, a meio do mandato, ao Dr. Rui Maria de Araújo, antigo membro de vários governos da Fretilin, abrindo espaço a uma nova geração de políticos que formaram o VI Governo Constitucional de Timor-Leste.

\section{A CPLP e a Globalização}

A preparação da Cimeira e, sobretudo, da Presidência Rotativa constituiu, para os líderes nacionais, um novo desafio e uma oportunidade para pôr em prática a nova dinâmica que 0 país propunha imprimir à Comunidade.

Apesar de haver já uma visão, importava juntar vontades e sinergias. Saber as aspirações da Comunidade para o futuro. Quais as expectativas que os outros países tinham da Presidência timorense, que, desde logo, iria acentuar a descontinuidade geográfica desta organização ao ser, pela primeira vez, dirigida a partir da Ásia. Mas, sobretudo, importava definir uma agenda consensual que se adequasse à Comunidade, atribuindo-lhe a sua verdadeira importância, enquanto "plataforma para a Globalização", como a definiu Ray Rala Xanana Gusmão na Conferência Científica Internacional sobre "Investigação, Educação, Cooperação e Desenvolvimento nos Países de Língua Oficial Portuguesa", em Díli, em 2014.

\footnotetext{
${ }^{4}$ O Plano Estratégico de Desenvolvimento está disponível, para consulta, no Portal do Governo de Timor-Leste, em http://timor-leste.gov.t//wp-content/uploads/2012/02/Plano-Estrategico-de-Desenvolvimento PT1.pdf.

E3 - Revista de Economia, Empresas e Empreendedores na CPLP | Volume 3 | Número 1
} 
Afirmou o então Primeiro-Ministro de Timor-Leste na XV Reunião dos Ministros da Defesa da CPLP, que decorreu em Lisboa, em maio de 2014:

\begin{abstract}
Usufruamos deste espaço de partilha fraterna para reforçar os vínculos de cooperação que assimilem uma real conceção do mundo como ele hoje se configure neste contexto de globalização, que vê estreitar a distância que nos separa abreviando a imensidão dos Oceanos, que faz dos desafios de uns os desafios de todos, e que faz dos nossos povos, afinal, uma grande comunidade de sonhos, de valores, de justiça social e de solidariedade humana.
\end{abstract}

Para além de dois périplos pela Comunidade, Timor-Leste convidou os outros sete Estadosmembros para, em conjunto, pensarem e planificarem a X Cimeira dos Chefes de Estado e do Governo e o programa da Presidência Rotativa (2014- 2016). Foi com espírito conciliador, de abertura e abrangência, numa iniciativa inédita e inovadora, que foi criada a Comissão de Preparação da Cimeira, com comissários de todos os países da CPLP, incluindo também o Secretariado Executivo, e presidida pelo Dr. Francisco Guterres "Lu-Olo", antigo presidente do Parlamento Nacional de Timor-Leste e Presidente da Fretilin.

O tema "A CPLP e a Globalização" e o mote "plantemos a bandeira da CPLP nos negócios do mundo e sejamos também mensageiros da paz, da defesa dos direitos humanos e da justiça social onde quer que estejamos representados" expressam claramente a visão de Timor-Leste, adaptando-se ao momento da história em que o mundo se tornou uma "aldeia" em progresso. A política, a economia, o comércio, a cultura, a facilidade de circulação física e, sobretudo, da informação e (consequentemente) das influências, passaram a fluir com a liberdade quase imparável das correntes marítimas ou com a circulação atmosférica, que, sem aparente ligação, ora desmontam ora acentuam forças e tendências.

Assim, a globalização da CPLP, aos olhos de Timor-Leste, não se devia fazer apenas como crescimento para uma nova região do mundo - a Ásia-Pacífico - deslocando o seu eixo, estabilizado, então, no Atlântico. Devia fazer-se dando novos objetivos e fomentando objetivos já idealizados que não tinham ainda tido oportunidade e tempo para crescer e progredir. A expansão económica e empresarial era o objetivo mais evidente. Identificado na Declaração Constitutiva da CPLP, o desenvolvimento da cooperação económica e empresarial foi, no entanto, inicialmente pensado para um universo constringido "entre si".

Este novo sentido de progresso floresceu da profunda reflexão, feita em conjunto, sobre os atuais desafios da CPLP, face à atual conjuntura de mudança. A importância crescente da congregação de esforços, através do fomento de grupos regionais com interesses e objetivos comuns, foi, portanto, uma janela de oportunidade para este grupo supra regional beneficiar desta mesma mudança.

A Presidência de Timor-Leste prometia, assim, ser uma presidência de transição, em que o ano de 2014 marcava de forma indelével a Comunidade. Ao completar 18 anos de existência, a CPLP cresceu ao aceitar um novo membro, a Guiné Equatorial, e ganhou importância geoestratégica e geoeconómica ao transferir a sua base para a Ásia-Pacífico - neste que foi já denominado como "o século asiático" -, mas também ao admitir quatro novos Observadores Associados: a Geórgia, o Japão, a República da Namíbia e a República da Turquia, que se juntaram à República da llha Maurícia e ao Senegal.

A nova visão de Timor-Leste não podia deixar, todavia, de congregar e dar continuidade ao trabalho desenvolvido pelas anteriores presidências. O programa manteve os objetivos traçados em 1996 - concertação político-diplomática, cooperação e reforço da língua portuguesa. Mas para além da componente económica e empresarial ter vindo a reforçar estes pilares, no biénio de 2014-2016 foi definida a "Nova Visão Estratégica da CPLP para 20162016", aprovada na XX Reunião Ordinária do Conselho de Ministros, que decorreu em Díli, e prometida pela Declaração resultante da X Cimeira de Chefes de Estado e de Governo.

Nos quase dois anos e meio de gestão Timorense, foram inúmeras as iniciativas que se desenvolveram na Comunidade, dentro e fora de Timor-Leste, dando cumprimento aos quatro eixos definidos no programa da Presidência timorense.

E3 - Revista de Economia, Empresas e Empreendedores na CPLP | Volume 3 | Número 1 


\section{Concertação político-diplomática}

Particularmente sensível à solidariedade e apoio em situações de dificuldade, Timor-Leste canalizou esforços para cumprir o "compromisso de reforçar os laços de solidariedade e de cooperação" entre os Estados-membros, tal como está expresso na Declaração Constitutiva da CPLP e, como são disso exemplo tomadas de posição face à Guiné Equatorial, o apoio à Guiné-Bissau, o apoio em vários setores como o da Justiça com Cabo Verde e Portugal, entre outros.

A primeira grande aposta da Presidência Timorense foi contribuir para a estabilização da Guiné-Bissau, uma missão que foi, desde logo, inscrita na Declaração que resultou da Cimeira de Díli. A Declaração sobre "A Situação da Guiné-Bissau"chamava à atenção para a necessidade de concertar ações de assistência ao país com outros parceiros internacionais e para a necessidade de acompanhamento da situação interna pelo Secretário Executivo da CPLP e seu Representante na Guiné-Bissau.

Atento ao desenvolvimento da crise política guineense, iniciada com o golpe de Estado de 2012, Timor-Leste moveu influências e concentrou esforços, a título individual e enquanto Presidente da CPLP, para, juntamente com as autoridades de Bissau e com parceiros internacionais (especialmente a Comunidade Económica dos Estados da África Ocidental CEDEAO, a União Europeia, a Organização das Nações Unidas, a União Africana e a Organização das Nações Unidas), garantir o regresso à normalidade. Parceiros estes que estiveram presentes no Conselho de Ministros Extraordinário da CPLP, realizado em Bissau, em outubro de 2014, quatro meses depois de Timor-Leste assumir a Presidência rotativa. Este encontro teve como objetivo avaliar a situação do país, após as eleições legislativas e presidenciais, decorridas em abril e maio, respetivamente, e encorajar as novas autoridades do país a prosseguir o diálogo para alcançar um consenso político à volta das prioridades nacionais.

No contexto deste apoio alargado à Guiné-Bissau, destacam-se duas importantes iniciativas que contaram com a participação ativa da CPLP de Timor-Leste: a X Reunião do Grupo de Contacto Internacional para a Guiné-Bissau, em Nova lorque, em novembro de 2014, e a Conferência Internacional de Parceiros da Guiné-Bissau, que se realizou em Bruxelas, em março de 2015. Esta conferência teve como grande objetivo a captação de fundos para 0 financiamento do Programa de Contingência desenvolvido pelas autoridades da Guiné-Bissau, assistência técnica e reforço das capacidades institucionais. Contou com a participação de 70 países e instituições e resultou na promessa de mais de mil milhões de euros em dinheiro, contribuição de bens e serviços, propostas de investimento e empréstimos, com taxas reduzidas para o financiamento dos projetos previstos no Plano Estratégico Operacional do Governo guineense. O Estado de Timor-Leste contribuiu com 1,9 milhões de dólares americanos para o financiamento de atividades implementadas pela Agência de Cooperação de Timor-Leste, sediada em Bissau. A contribuição foi anunciada pelo Ministro dos Negócios Estrangeiros e Cooperação de Timor-Leste, Hernâni Coelho, que, em nome da CPLP, deu a conhecer, também, a criação da rubrica "Cooperação da CPLP com a Guiné-Bissau" no Fundo Especial da Comunidade, destinada unicamente à cooperação com aquele país.

Murade Murargy, Secretário Executivo da CPLP, no relatório do biénio 2014-2016, apresentado na XI Conferência de Chefes de Estado e de Governo que decorreu em Brasília, em novembro de 2016, na qual o Brasil assumiu a Presidência Rotativa da CPLP, salientou "que Timor-Leste assegurou um importante apoio técnico e financeiro ao processo eleitoral, nomeadamente no recenseamento de eleitores". Acrescente-se que, já em 2013, o então Primeiro-Ministro Xanana Gusmão tinha criado a Missão de Apoio ao Processo Eleitoral na Guiné-Bissau com um financiamento do Estado timorense no valor de seis milhões de dólares americanos.

Em fevereiro de 2016, o Presidente do Conselho de Ministros e o Secretário Executivo da CPLP realizaram uma visita à Guiné-Bissau para acompanhar, de perto, o desenvolvimento da situação política no país. Nesse mesmo mês, foi solicitado pelo Representante Permanente da 
Guiné-Bissau, junto da CPLP em Lisboa, que se deixasse de incluir este tema na agenda do Comité de Concertação Permanente.

O apoio diplomático da CPLP para com os seus Estados-membros na questão política foi também visível, neste biénio, com o acompanhamento das eleições em Moçambique e São Tomé e Príncipe, em outubro de 2014. Atestou-se, para ambos os países, o cumprimento da legislação e dos critérios internacionais. As eleições presidenciais de 2016 na Guiné Equatorial contaram com uma missão de observação da CPLP, realizada a convite das autoridades de Malabo, que constatou o cumprimento dos parâmetros democráticos.

Nos últimos anos, foi notória a intensificação do diálogo e da interação com os Observadores Associados, resultando num maior apoio externo à CPLP e, paralelamente, num crescente interesse por parte de outros Estados na obtenção desta categoria. Entre 2015 e 2016, a Hungria, a República Checa a República Eslovaca e a República Oriental do Uruguai apresentaram candidatura, tendo sido aceites na Cimeira de Brasília, no término da Presidência timorense, aumentando para dez o número de Observadores Associados. Israel e Marrocos manifestaram interesse formal em obter, de igual modo, o estatuto durante o biénio de 2014-2016. A Turquia, aceite na Cimeira de Díli, em 2014, apoiou formalmente o projeto de cooperação entre a Comunidade e as Nações Unidas, apresentada, em 2015, na 70. a Sessão da Assembleia Geral da ONU.

Paralelamente a este evento, em Nova lorque e também, em 2016, na 71. a Sessão da Assembleia Geral das Nações Unidas, o Conselho de Ministros da CPLP reuniu informalmente para debater assuntos relevantes para a Comunidade, dando, assim, estratégia e forma à voz dos nove perante as outras nações.

Da Reunião Informal do Conselho de Ministros de 2016, destaca-se a satisfação manifestada no seio da CPLP face aos desenvolvimentos registados na Guiné Equatorial, nomeadamente no que diz respeito ao processo de ratificação dos estatutos da CPLP, a efetiva abolição da pena de morte do ordenamento jurídico nacional e a implementação da língua portuguesa neste Estado-Membro. Destaca-se, igualmente, o acompanhamento atento das reivindicações de Timor-Leste, no quadro da prevalência do direito internacional, em matéria de delimitação de fronteiras marítimas, especialmente o processo de Conciliação Obrigatória, tendo 0 Conselho de Ministros da CPLP felicitado Timor-Leste por incentivar o diálogo permanente com a Austrália. A eleição do Eng. ․ António Guterres para o cargo de Secretário-geral das Nações Unidas foi também, naturalmente, apreciada.

Atenta à agenda internacional, a Presidência timorense procurou, assim, criar condições de diálogo e de concertação para garantir uma coordenação mais eficaz das posições dos Estados-Membros da CPLP e da sua promoção junto, não só das grandes organizações mundiais, mas também das organizações regionais, especialmente a ASEAN (Associação das Nações do Sudeste Asiático), aproveitando a deslocação da gestão da Comunidade para Timor-Leste.

\section{Cooperação para o desenvolvimento}

Pilar fundamental da CPLP, sobre o qual têm vindo a ser fortalecidos laços de relacionamento entre os Estados-membros, a cooperação para o desenvolvimento foi um dos eixos que registou grandes progressos durante o biénio 2014-2016. Evidência deste progresso e, sobretudo, da vontade de conciliação de ideias é a realização de 15 reuniões ministeriais setoriais em diferentes domínios de intervenção, durante estes dois anos.

$\mathrm{Na}$ Reunião dos Pontos Focais de Cooperação, que antecedeu a Cimeira da Brasília em outubro de 2016, foi feita uma avaliação do nível de execução técnica e financeira do Plano Indicativo de Cooperação (PIC), "tendo observado um grau de eficiência e eficácia bastante satisfatório das atividades em execução ou em fase de conclusão".

Na nota informativa sobre as conclusões deste encontro, os Pontos Focais observam que:

[...] em julho de 2016, o agregado global de execução do Programa Indicativo de Cooperação (PIC) superou o valor histórico de 13 milhões de Euros. Tal indicador revela

E3 - Revista de Economia, Empresas e Empreendedores na CPLP | Volume 3 | Número 1 
que o "pilar cooperação" tem vindo a crescer de forma sustentada, desde que o Fundo Especial teve o seu início, em 2000. Este pilar constitui-se hoje como um dos vetores de dinamismo da Organização.

A aplicação da Agenda 2030 para o Desenvolvimento Sustentável - Transformando o Nosso Mundo, aprovada em Nova lorque, em setembro de 2015, para a erradicação da pobreza extrema, em todas as suas formas e dimensões, foi também analisada pelos Pontos Focais de Cooperação. No entanto, é de salientar que "a aprovação do documento 'Cooperação na CPLP - uma visão estratégica no pós 2015', em julho de 2015, antecipou este acordo global e permitiu demonstrar o amadurecimento do debate sobre as dinâmicas de cooperação da Comunidade e um importante esforço de coordenação e concertação", como refere o Secretário Executivo, Murade Murargy, no seu relatório sobre o biénio 2014-2016.

A aprovação da Estratégia Geral de Cooperação da CPLP, em 2006, em Bissau - de orientação dos projetos e programas do Plano Indicativo da Cooperação - foi um passo importante para a coordenação e harmonização desta área. Nos últimos anos, a aplicação do PIC tem vindo a mostrar a importância estratégica deste pilar para o diálogo político e para a operacionalização de projetos na Comunidade. Esta importância revela-se também na visibilidade e reconhecimento do papel da CPLP em domínios como a Saúde, a lgualdade de Género e Empoderamento da Mulher, a Segurança Alimentar e Nutricional, o Ambiente, a Ciência, Tecnologia e Ensino Superior, Direitos Humanos e Energia.

A criação dos Planos Estratégicos de Cooperação Setorial para as áreas relevantes do processo de desenvolvimento sustentável da Comunidade, revelou-se uma boa aposta para o fortalecimento da CPLP, tornando-a mais moderna e credível, aproximando-a, assim, dos parceiros internacionais. As conquistas são já notórias, mas o potencial é ainda enorme, quer de crescimento interno, quer de afirmação para o exterior. O Plano Estratégico da Cooperação em Saúde da CPLP, aprovado em 2009, por exemplo, é considerado um modelo de boas práticas por parceiros internacionais, como o Banco Mundial e a Organização Mundial da Alimentação (FAO).

As metas definidas para a igualdade de género, para o trabalho e proteção social (de onde se destaca a extensão da proteção social e o compromisso no combate contra o trabalho infantil), para os direitos humanos, para a juventude e desporto, para o ambiente, mares e oceanos, e para o turismo, são exemplo do empenho impresso ao desenvolvimento na Comunidade. Neste biénio (2014-2016), realizaram-se três reuniões da Conferência de Ministros da Juventude e Desporto, duas edições de Jogos Desportivos, uma bienal de Jovens Criadores e um Fórum da Juventude. $O$ envolvimento ativo dos jovens da Comunidade expressa-se, por exemplo, na associação à Campanha Juntos Contra a Fome.

A Declaração de Díli, que resultou da quarta reunião dos responsáveis pela igualdade de género, realizada em maio de 2016, reconhece "que o empoderamento económico das mulheres e a sua autonomia económica, designadamente através do empreendedorismo feminino", são factores essenciais "para alcançar os Objetivos de Desenvolvimento Sustentável e as metas da Agenda 2030, nomeadamente para a erradicação da pobreza".

A Segurança Alimentar e Nutricional, expressa no lema da Presidência Rotativa de Moçambique (2012-2014), foi também alvo de significativos progressos. Desde logo, com o compromisso assumido na Cimeira de Díli em manter o tema na agenda da CPLP até 2025. Do biénio da gestão timorense destaca-se, no entanto, a I Reunião Extraordinária do Conselho de Segurança Alimentar e Nutricional (CONSAN-CPLP) que, pela primeira vez, juntou autoridades governamentais, parlamentares, organizações da sociedade civil, representantes do setor privado e universidade e pesquisadores de todos os países membros da CPLP, na capital timorense. Neste encontro subordinado ao tema "Erradicação da Fome e da Desnutrição na CPLP", que decorreu em novembro de 2015, em Díli, foi aprovado o Plano Indicativo de Atividades conjuntas da Estratégia de Segurança Alimentar e Nutricional (ESAN-CPLP). Destaca-se, também, o alargamento da visibilidade da campanha "Juntos Contra a Fome", que, em duas edições (2014 e 2015) e com o apoio do Secretário Executivo, juntou em Portugal um 
amplo apoio na "Corrida Juntos Contra Fome". A Segurança Alimentar e Nutricional da CPLP conta com a colaboração da FAO, através de um projeto de cooperação, iniciado em 2014, para a realização de atividades de assistência técnica na Guiné-Bissau, São Tomé e Príncipe e Timor-Leste.

Aliado importante da CPLP, a sociedade civil desempenha um papel fundamental neste pilar, com expressão máxima através do estatuto de Observador Consultivo, categoria atribuída desde 2005 a organizações da sociedade civil que se empenham na prossecução dos objetivos da Comunidade, reforçando, assim, a estratégia de cooperação. Durante a Presidência Rotativa de Timor-Leste, foi notório o esforço de fortalecimento da representação e importância deste grupo (que conta já com mais de setenta organizações), nomeadamente através da IX Reunião dos Observadores Consultivos da CPLP e do II Fórum da Sociedade Civil.

$\mathrm{Na}$ cooperação para a área dos Mares e Oceanos, teve lugar, em 2015, a II Reunião Extraordinária dos Ministros dos Assuntos do Mar, onde se salientou a necessidade de concertação politico-diplomática e cooperação neste setor e a criação de um Plano de Ação. Logo, em maio de 2016, os Ministros aprovaram, na Reunião que decorreu em Díli, o Plano de Ação para a implementação da Estratégia da CPLP para os Oceanos, do qual se destaca o incentivo à investigação científica nas diversas áreas ligadas ao mar e à partilha de conhecimento, o estabelecimento de um Atlas multimédia de acesso livre, para aumento de conhecimento da sociedade civil sobre os oceanos, e o estabelecimento de uma parceria para o Lixo Marinho, para prevenção e redução do lixo proveniente de fontes terrestres e marinhas.

A amplitude da Comunidade que constitui um espaço descontínuo, não só em termos geográficos, mas também de desenvolvimento, capacidade e influência, é um desafio transversal à concretização dos objetivos estabelecidos em 1996. O eixo da cooperação para o desenvolvimento tem-se revelado uma conquista e um potencial de expansão. É, para isso, fundamental apostar na capacitação institucional e na valorização do potencial humano em todos os Estados-membros.

\section{A cooperação económica e empresarial}

Uma das iniciativas que ganha relevo no biénio 2014-2016, pelo dinamismo e empenho com que foi desenvolvida e pelos resultados alcançados, é, precisamente, a vertente económica e empresarial com ponto alto na realização do Primeiro Fórum Económico Global. Desenvolvido com o apoio da Confederação Empresarial da CPLP (CE-CPLP) e da União de Exportadores da CPLP (UE-CPLP), este evento juntou, em Díli, delegações de mais de 20 países e centenas de empresas e investidores de países da Comunidade e de outros não pertencentes à Comunidade. Participaram, tal como foi inicialmente previsto pela organização e seria, de resto, previsível por se realizar na Ásia, delegações de países da Associação de Nações do Sudeste Asiático (ASEAN) - "uma das mais dinâmicas regiões de integração económica global" 1 . Especificamente, estiveram representados neste encontro, decorrido no início de $2016 \mathrm{em}$ paralelo com a II Reunião de Ministros do Comércio da CPLP, países de várias regiões do globo, entre os quais Angola, Austrália, Brasil, Brunei, Cabo Verde, Camboja, Cazaquistão, Espanha, Guiné-Bissau, Guiné Equatorial, Indonésia, Malásia, Moçambique, Portugal, São Tomé e Príncipe, Singapura, Tailândia e Vietname.

Por via deste certame, criado e organizado por Timor-Leste, concretizaram-se, em apenas dois dias, quase 300 encontros entre empresas privadas (B2B ${ }^{5}$ ), com a realização, no local, demais de duas dezenas de negócios. Celebraram-se três acordos entre associações empresariais e continuam a desenvolver-se muitos contactos e negociações entre os vários participantes de países pertencentes e não pertencentes à CPLP.

É precisamente esta a novidade impressa por Timor-Leste: a abertura da Comunidade a uma região que "é atualmente o eixo económico, financeiro e estratégico do mundo" 6 , facilitando aos

\footnotetext{
${ }^{5}$ Business to business.

${ }^{6}$ In: "A Presidência de Timor-Leste da CPLP: uma Visão para o Futuro" - Alocução de Sua Excelência o PrimeiroMinistro da República Democrática de Timor-Leste, Kay Rala Xanana Gusmão (a poucos dias de o país assumir a E3 - Revista de Economia, Empresas e Empreendedores na CPLP | Volume 3 | Número 1
} 
empresários privados uma oportunidade ímpar de se darem a conhecer e expandir-se para novos territórios.

A repercussão desta iniciativa representa, em termos imediatos, a estruturação de um novo pilar para a CPLP: o pilar económico e empresarial. Mas, a longo prazo, abre novas portas para a concretização e reforço de vários objetivos da CPLP, como o combate à pobreza ou 0 desenvolvimento, tal como, de resto, ambicionou Timor-Leste, ao desenhar a sua agenda da Presidência Rotativa:

\begin{abstract}
[...] é um desafio, considerando as características heterogéneas e as próprias realidades económicas, sociais e políticas de cada um dos nossos Estados, mas os ganhos poderão ser vantajosos quer em termos de expansão de mercados quer de fluxos de investimento e, sobretudo, em termos de transferência de conhecimentos e experiências que poderão levar ao desenvolvimento de novas ideias e contribuir para este novo paradigma económico global.
\end{abstract}

Outro setor a que Timor-Leste dedica especial atenção, e que merece também destaque, é o da energia e recursos minerais, com a concretização da Primeira Conferência da Energia para - Desenvolvimento da CPLP, que decorreu paralelamente à Reunião de Ministros da Energia da CPLP, em 2015, em Portugal, e da Primeira Reunião Técnica da Energia da CPLP, em 2016, na Guiné Equatorial, tendo este sido o derradeiro evento organizado durante a Presidência Timorense. Para além de dar mais significado à expressão da CPLP "nos negócios do mundo", reforçando a cooperação na Comunidade, Timor-Leste viu, assim, ser concretizada a união de sinergias para uma área que representa ainda, para muitos países, incluindo este novo Estado, um pilar de sustentação económica: os hidrocarbonetos.

É, portanto, inegável que o tema dos recursos energéticos mereça subir na agenda dos assuntos da Comunidade. Não pode ser ignorado o facto de o Brasil e Angola pertencerem aos vinte maiores produtores de petróleo do mundo. Tal como não podem ser ignoradas as recentes descobertas de gás natural em Moçambique. Segundo a consultora PricewaterhouseCoopers, "Moçambique pode rivalizar com a Austrália no setor do gás natural e ficar perto do maior produtor mundial, o Qatar, se conseguir captar o investimento externo necessário para as infraestruturas". São Tomé e Príncipe pode tornar-se, também, exportador de recursos minerais, devido às reservas na sua zona marítima conjunta com a Nigéria. TimorLeste e a Guiné Equatorial são dois dos países mais dependentes das receitas minerais.

Salientou, em 2014, o então Primeiro-Ministro de Timor-Leste, atual Ministro do Planeamento e Investimento Estratégico:

Atendendo à importância dos recursos naturais (especialmente o gás natural e o petróleo) para os países da CPLP, esta é uma área em que os países da comunidade estão expostos a riscos externos, tal como demonstrado pela baixa nos preços internacionais de petróleo aquando da crise financeira mundial recente. Isto implica que é uma área onde pode haver espaço de cooperação em termos de gestão dos fundos, mecanismos de mitigação dos choques, combate à evasão fiscal e intercâmbio de experiências em várias áreas [...]. ${ }^{7}$

\title{
A promoção da língua portuguesa
}

Como eixo, à volta do qual circulam todos os outros na CPLP, e base da criação da organização, a língua portuguesa tem vindo a ganhar importância na comunicação internacional com reconhecido valor, enquanto língua de ciência e tecnologia, estando a aumentar a sua utilização no ciberespaço.

Presidência Rotativa), por ocasião do seminário "Globalização Económica e Oportunidades de Investimento: a CPLP e a Região da Ásia-Pacífico", 24 de julho de 2014, Centro de Convenções de Díli.

7 In: "Política de Timor-Leste na Liderança da CPLP: uma Visão Global para o Futuro" - Discurso de Sua Excelência o Primeiro-Ministro, Kay Rala Xanana Gusmão, por ocasião da Conferência Científica Internacional sob o tema "Investigação, Educação, Cooperação e Desenvolvimento nos Países de Língua Oficial Portuguesa", 16 de julho de 2014, Universidade Nacional Timor Lorosa'e (UNTL), Centro de Convenções de Díli.

E3 - Revista de Economia, Empresas e Empreendedores na CPLP | Volume 3 | Número 1 
Fortemente ligada à identidade de Timor-Leste, esta é, no entanto, uma questão ambígua para o país. Distante dos restantes países falantes de Português e proibido o seu uso durante mais de duas décadas pelas forças indonésias, o povo timorense nunca deixou de a considerar como sua, adotando-a como língua da resistência e, mais tarde, na Constituição, como língua oficial. A sua promoção no país tem sido uma prioridade para os sucessivos governos.

"De todos os Estados-membros, Timor-Leste é o mais deficitário na variável do uso e domínio desta língua" ${ }^{8}$, salientou Xanana Gusmão, na apresentação da Política de Timor-Leste na Liderança da CPLP: uma Visão Global para o Futuro", acrescentando que, "mais do que o valor simbólico que the atribuímos pelo papel fundamental que desempenhou durante o nosso período de luta pela independência, é agora também instrumento importante de identidade geopolítica". A língua portuguesa é, para Timor-Leste, uma "ferramenta de singularidade" na região da Ásia-Pacífico, em conjunto com a língua Tétum que absorve influências do português.

Foi, assim, evidente o esforço da Presidência Timorense em "promover novas iniciativas no sentido de reforçar e promover a posição da língua portuguesa no sistema mundial" ${ }^{10}$, nomeadamente através da aprovação, nas Reuniões Ministeriais Setoriais de 2014 e 2016, dos Planos Estratégicos e dos Planos de Ação, que orientam a Direção para a Ação Cultural e Língua Portuguesa até 2020, e da aproximação à sociedade civil.

Foram iniciados projetos que revelam a conformidade do alinhamento entre a cooperação multilateral e as prioridades nacionais dos Estados-Membros, nomeadamente o Programa CPLP Audiovisual, o Vocabulário Ortográfico Comum, o Portal do Professor de Português Língua Estrangeira / Língua Materna, o Portal da Educação da CPLP eo Portal do Ensino Superior, Ciência e Tecnologia. A Comissão Nacional de Timor-Leste para o Instituto Nacional de Língua Portuguesa desenvolveu, por seu lado, iniciativas que merecem destaque, na prossecução dos objetivos traçados pela Presidência Rotativa de Timor-Leste, mais precisamente, o Vocabulário Ortográfico Nacional de Timor-Leste, que integra o Vocabulário Ortográfico Comum e a elaboração das 56 unidades didáticas disponíveis no Portal do Professor Português Língua Estrangeira/Língua Não Materna.

A III Conferência Internacional sobre o Futuro da Língua Portuguesa no Sistema Mundial decorreu em Díli, em junho de 2016, envolvendo países da região com crescente interesse na língua portuguesa. A Conferência foi precedida de dois eventos: o Colóquio da Praia "Língua Portuguesa: Ações e Projeções" e o Colóquio de Díli "A Língua Portuguesa e a Globalização", onde foram debatidos os eixos prioritários das políticas da língua portuguesa nos Estadosmembros.

\section{Nova visão estratégica}

Entre 2014 e 2016, foi cumprida a realização da Nova Visão Estratégica para a CPLP para os próximos dez anos, uma decisão assumida na Cimeira de Díli, no arranque da Presidência de Timor-Leste. O documento foi adotado na Cimeira de Brasília no término da Presidência Timorense.

Ao longo de dois anos, o grupo de trabalho criado para a execução desta missão (GT Visão), composto por elementos de todos os Estados-membros, analisou a organização e 0 funcionamento da CPLP. Identificou as áreas de potencial, onde foram obtidos mais sucessos, e os desafios que se avizinham. Definiu linhas de orientação, metas e objetivos tangíveis, tendo em conta as prioridades e o interesse coletivo dos Estados-membros.

\footnotetext{
${ }^{8}$ A par com a Guiné-Equatorial que, na altura daquele discurso, ainda não era Estado-membro.

${ }^{9}$ In: "Política de Timor-Leste na Liderança da CPLP: uma Visão Global para o Futuro" - Discurso de Sua Excelência o Primeiro-Ministro, Kay Rala Xanana Gusmão, por ocasião da Conferência Científica Internacional sob o tema "Investigação, Educação, Cooperação e Desenvolvimento nos Países de Língua Oficial Portuguesa", 16 de julho de 2014, Universidade Nacional Timor Lorosa'e (UNTL), Centro de Convenções de Díli.

10 In: "Política de Timor-Leste na Liderança da CPLP: uma Visão Global para o Futuro" - Discurso de Sua Excelência o Primeiro-Ministro, Kay Rala Xanana Gusmão, por ocasião da Conferência Científica Internacional sob o tema "Investigação, Educação, Cooperação e Desenvolvimento nos Países de Língua Oficial Portuguesa", 16 de julho de 2014, Universidade Nacional Timor Lorosa'e (UNTL), Centro de Convenções de Díli.

E3 - Revista de Economia, Empresas e Empreendedores na CPLP | Volume 3 | Número 1
} 
A nova visão estratégica assentou forma, no início de 2016, com o endosso, pelo Conselho de Ministros, da "Declaração sobre a Nova Visão Estratégica da CPLP (2016-2016)". O documento, aprovado na XI Cimeira de Chefes de Estado e de Governo, em Brasília no final do ano, define como principais áreas de aposta: a "cooperação económica e empresarial, segurança alimentar e nutricional, energia, turismo, ambiente, oceanos e plataformas continentais, cultura, educação e ciência, tecnologia e ensino superior". Haverá uma maior promoção no envolvimento da sociedade civil nas atividades da comunidade e um reforço da cooperação multilateral com programas concretos para o desenvolvimento sustentável e com o objetivo de melhorar as condições de vida das populações e promover o emprego. Em relação à língua, a nova visão quer "valorizar o potencial das diásporas da CPLP e das comunidades situadas noutros países e regiões do mundo, que preservam a influência da língua portuguesa e partilham laços históricos e culturais com os países da organização".Serão feitos esforços para facilitar a circulação de pessoas (especialmente de estudantes e académicos de língua portuguesa), e ainda de bens e serviços no espaço comunitário.

Esta nova visão estratégia resulta da necessidade de reposicionar a Comunidade face às "alterações ocorridas na conjuntura político-económica no âmbito mundial e às mudanças internas nos Estados-membros", lê-se na "Declaração sobre a Nova Visão Estratégica da CPLP (2016-2016)". O documento acrescenta que "a integração dos países-membros da CPLP em diferentes regiões do mundo, a existência de uma extensa área marítima, o considerável potencial económico e estratégico representado pelo mar, as perspetivas favoráveis no domínio energético e a diversidade cultural" constituem "um importante património comum que deve ser continuamente valorizado e potenciado em benefício da comunidade".

A otimização do funcionamento da CPLP, concertado e dirigido aos objetivos comuns para um posicionamento sólido enquanto parceiro de relações internacionais, contribuirá certamente para a conquista de benefícios, quer para o conjunto, quer para cada um dos nove Estados. É esta a herança que Timor-Leste procurou passar para o seu sucessor, o Brasil, que assumiu, pela segunda vez, a Presidência da CPLP, no dia 1 de novembro de 2016, na XI Conferência de Chefes de Estado e de Governo, decorrida em Brasília. 